\title{
Strategies for Feeding the Preterm Infant
}

\author{
William W. Hay, Jr. \\ Perinatal Research Center, Department of Pediatrics, Colorado Clinical Translational Science Institute, \\ University of Colorado School of Medicine, University of Colorado Denver, Aurora, Colo., USA
}

\section{Key Words}

Nutrition · Feeding $\cdot$ Preterm infant $\cdot$ Oxygen $\cdot$ Glucose $\cdot$ Amino acids $\cdot$ Lipids $\cdot$ Insulin $\cdot$ Minimal enteral nutrition $\cdot$ Intravenous feeding $\cdot$ Intrauterine growth restriction

\begin{abstract}
According to many experts in neonatal nutrition, the goal for nutrition of the preterm infant should be to achieve a postnatal growth rate approximating that of the normal fetus of the same gestational age. Unfortunately, most preterm infants, especially those born very preterm with extremely low birth weight, are not fed sufficient amounts of nutrients to produce normal fetal rates of growth and, as a result, end up growth-restricted during their hospital period after birth. Growth restriction is a significant problem, as numerous studies have shown definitively that undernutrition, especially of protein, at critical stages of development produces long-term short stature, organ growth failure, and both neuronal deficits of number and dendritic connections as well as later behavioral and cognitive outcomes. Furthermore, clinical follow-up studies have shown that among infants fed formulas, the nutrient content of the formula is directly and positively related to mental and motor outcomes later in life. Nutritional requirements do not stop at birth. Thus, delaying nutrition after birth 'until the infant is stable' ignores the fundamental point that without nutrition starting immediately after birth, the infant enters a catabolic condition, and catabolism does not contribute to normal development and growth. Oxygen is necessary for all metabolic processes. Recent trends to limit oxygen supply to prevent oxygen toxicity have the potential, particularly when the
\end{abstract}

blood hemoglobin concentration falls to less than $8 \mathrm{~g} / \mathrm{dl}$, to develop growth failure. Glucose should be provided at 6-8 $\mathrm{mg} / \mathrm{min} / \mathrm{kg}$ as soon after birth as possible and adjusted according to frequent measurements of plasma glucose to achieve and maintain concentrations $>45 \mathrm{mg} / \mathrm{dl}$ but $<120$ $\mathrm{mg} / \mathrm{dl}$ to avoid the frequent problems of hyperglycemia and hypoglycemia. Similarly, lipid is required to provide at least $0.5 \mathrm{~g} / \mathrm{kg} /$ day to prevent essential fatty acid deficiency. However, the high rate of carbohydrate and lipid supply that preterm infants often get, based on the incomplete assumption that this is necessary to promote protein growth, tends to produce increased fat in organs like the liver and heart as well as adipose tissue. More and better essential fatty acid nutrition is valuable, but more organ and adipose fat has no known benefit and many problems. Amino acids and protein are essential not only for body growth but for metabolic signaling, protein synthesis, and protein accretion. 3.5-4.0 $\mathrm{g} / \mathrm{kg} /$ day are necessary to produce normal protein balance and growth in very preterm infants. Attempts to promote protein growth with insulin has many problems - it is ineffective while contributing to even further organ and adipose tissue fat deposition. Enteral feeding always is indicated and to date nearly all studies have shown that minimal enteral feeding approaches (e.g., 'trophic feeds') promote the capacity to feed enterally. Milk has distinct advantages over formulas in avoiding necrotizing enterocolitis (NEC), and while feeding is associated with NEC, minimal enteral feeding regimens produce less NEC than those geared towards

Presented at the International Symposium 'Recent Advances in Neonatal Medicine', Würzburg, 2008.

\section{KARGER}

Fax +41613061234 E-Mail karger@karger.ch www.karger.com
(C) 2008 S. Karger AG, Basel

$1661-7800 / 08 / 0944-0245 \$ 24.50 / 0$

Accessible online at:

www.karger.com/neo
William W. Hay, MD, Perinatal Research Center

Department of Pediatrics, Colorado Clinical Translational Science Institute

University of Colorado School of Medicine, University of Colorado Denver

13243 East 23rd Avenue, PO Box 6508, Aurora, CO 80045 (USA)

Tel. +1 303724 1400, Fax +1 303724 0898,E-Mail bill.hay@uchsc.edu 
more aggressive introduction of enteral feeding. Finally, overfeeding has the definite potential to produce adipose tissue, or obesity, which then leads to insulin resistance, glucose intolerance, and diabetes. This scenario occurs more commonly as infants are fed more and gain weight more rapidly after birth, regardless of their birth weight. Infants with IUGR and postnatal growth failure may be uniquely 'set up' for this outcome, while infants with in utero obesity, such as infants of diabetic mothers, already are well along this adverse outcome pathway. C Copyright $\odot 2008$ S. Karger AG, Basel

\section{Introduction}

Over the past 20 years, neonatal mortality rates for preterm infants, particularly those born extremely preterm (23-28 weeks' gestational age) and of very low birth weight $(<1,000 \mathrm{~g})$, have decreased steadily. Most of the major advances in this remarkable improvement have come from specialized techniques, such as high-frequency ventilation, continuous positive airway pressure applications, prenatal corticosteroid treatment of the mother about to deliver, postnatal artificial surfactant treatment, and an increasingly sophisticated array of medications. Improved experience of neonatologists, neonatal nurses, and many other healthcare workers has played a major role. Added to this growing capacity to improve healthcare of such fragile infants also includes an expanding array of nutritional strategies, including new formulas, supplements to milk, and intravenous nutrient solutions. Active research now is determining the most effective of these nutritional strategies, and to determine which of these strategies, as well as their optimal use, lead to the most effective outcomes in terms of body growth, body composition, and neurodevelopmental outcomes. Several recent reviews provide excellent in depth coverage of this topic [1-7].

\section{Goal of Nutrition for Preterm Infants}

Most neonatologists have accepted the recommendation of the American Academy of Pediatrics that growth of the postnatal preterm infant, both their anthropometric indices and body composition, should be the same as the normal fetus of the same gestational age growing in its mother's uterus [8]. While an imperfect guideline, since clearly there are different energy expenditures imposed by the neonatal intensive care environment and many diseases and adverse conditions that such infants experience, the normally growing fetus provides a reasonable estimate of the nutrition it would take to at least provide for such growth. It is, therefore, a guideline, not a requirement.

\section{Consequences of Not Meeting the Goal of Normal Fetal Growth Rate}

With such a guideline, though, how well are we doing in terms of feeding preterm infants and achieving the goal of the normal rate of fetal growth? Clearly, data from all around the world indicate that we have considerable room for improvement, as the growth of nearly all preterm infants, especially those at the earliest gestational ages and lowest birth weights, lags behind fetal growth curves during the period between their birth and term gestational age, when nearly all are, as a result, growthrestricted $[9,10]$. The same phenomenon was observed over 60 years ago, indicating that despite major advances in neonatology, strategies to nourish preterm infants and achieve better rates of growth has not kept pace with their survival [11].

Why is this the case? The principal answer appears to be that, for a variety of reasons (but not intent), neonatologists have not fed infants enough protein and enough energy to meet the requirements for fetal growth. Over time, therefore, preterm infants accumulate large protein and calorie deficits (negative areas under the nutrient requirement minus nutrient intake vs. time relationships), which so far have only been ameliorated, not removed by more appropriate and complete nutritional regimens [12].

Why is slower than normal rate of growth in preterm infants from insufficient nutrition a problem? Many studies now show clearly that specific nutritional deficits at critical stages of development limit fundamental components of growth that have long-lasting influences. Smart $[13,14]$ showed years ago that undernutrition of rat fetuses reduced brain growth overall as well as neuronal number and synapses, leading to later life reductions in brain size, cognitive capacity, and specific behaviors, such as learning. More recently, several groups have shown that brain growth of preterm infants is less than that of normally grown infants born at term, that this reduced brain growth is associated with cognitive delays, and that nutrition of the preterm infant with enriched diets (supplemented milk or preterm formulas, both with more protein) leads to larger brains and improved cognitive function, even into adolescence [15-17]. 


\section{Requirement for Early, Complete Intravenous Feeding}

At this point, therefore, it is essential to determine how we might further improve nutrition of preterm infants to eliminate the negative outcomes of poor growth associated with undernutrition. Two principal strategies are: (1) to start 'complete' nutrition earlier after birth to better maintain immediate postnatal growth at the previous fetal rate, and (2) to continue gestational age-appropriate amounts of nutrition to maintain preterm neonatal growth at fetal rates. Both of these basic strategies assume that it probably is impossible to start enteral feeding right after birth and provide enough nutrition for all or even a major part of the preterm infant's nutritional needs. This means that intravenous nutrition must be started immediately after birth and provide all of the nutrition that these infants need, only gradually decreasing as enteral feeding is increased successfully [5].

There are several general principles of early intravenous feeding in preterm infants [5]. These primarily note that metabolic and nutritional requirements do not stop with birth and, therefore, that intravenous feeding always is indicated when normal metabolic and nutritional needs are not met by normal enteral feeding. Hours, not days, are the longest periods infants should be allowed to not receive nutrition after birth, intravenously or enterally, and the metabolic and nutrient requirements of the newborn are at least equal to or greater than those of the fetus.

\section{Nutrient Requirements for Preterm Infants}

If we are going to match preterm neonatal growth to fetal growth, which 'fetal nutrients' should we include and how much of each should we use to achieve fetal growth rates and prevent postnatal growth restriction? Basic to all nutritional strategies are the appropriate amounts of the essential nutrients, glucose, lipids, and amino acids. Oxygen also is essential for growth, and in fetal life, insulin is the primary anabolic hormone [2-4].

\section{Oxygen}

Several studies have documented that with sustained fetal hypoxia produced from maternal hypoxia, fetal protein synthesis decreases more than protein breakdown, leading to a reduction in net protein accretion [18]. In the pregnant mother exposed to hypoxia, however, reduced oxygen supply to the active or energy-dependent amino acid transporters doubly limits the capacity for protein synthesis in the fetus, first by diminishing active transport of amino acids into the fetus and second by diminishing protein synthesis itself, a result of molecular oxygen insufficiency. The latter has been defined in a variety of in vitro conditions [19]. Friedman, for example, showed that hypoxia prevented insulin from stimulating fetal eIF4e expression (eIF4e, or eukaryotic initiation factor 4 e), a primary molecular protein synthesis regulator, in primary fetal hepatocytes at low, normal, and hyperglycemic glucose concentrations [J. Friedman et al., unpubl. data, University of Colorado School of Medicine, Aurora, Colo., USA, 2008]. In vivo, both animal and human studies have shown that fetal or neonatal growth rate will diminish to the extent that blood oxygen content is not maintained, either by producing anemia (withdrawing blood and removing red blood cells and replacing the remaining plasma in experimental animals) or by allowing anemia to develop (from blood draws for biochemical, blood gas, and hematological measurements in preterm infants) [20]. Furthermore, when anemia is prevented from developing in preterm infants (limiting blood draws, use of iron and erythropoietin treatments, and transfusion) or in experimental animals when red blood cell production and thus blood oxygen content naturally increase in response to hypoxia, growth is maintained at or closer to normal fetal growth rates at the same gestational age $[21,22]$. It is possible, therefore, that if one allows preterm infants to be more anemic (hematocrits in the low $20 \mathrm{~s}, \mathrm{Hgb}<8 \mathrm{~g} / \mathrm{dl}$ ) to limit transfusion risks and also to have lower $\mathrm{PaO}_{2}$ values to reduce oxygen toxicity [23], growth restriction might become a more important problem. In this case, it remains to be determined if more aggressive provision of nutrients for energy production and protein synthesis will prevent or, alternatively, even worsen growth restriction more than what already occurs. These are important and untested questions, particularly in light of many previous unsuccessful attempts to improve fetal growth in pregnancies with intrauterine growth restriction (IUGR) by maternal nutrient supplementation, particularly of protein $[24,25]$. Clearly, this is one of the most important areas for future research in both fetal and neonatal nutrition, especially when oxygen supply is limited.

\section{Glucose}

Fetal studies in animal models have shown that fetal whole-body glucose utilization rates are twice as high early in gestation, about the same time that the earliest human preterm infants survive, as they are close to term 
[26]. At earlier gestations, the largest glucose-consuming organ is the brain, which accounts for nearly all of wholebody glucose utilization rate [24]. As development proceeds over the latter third of gestation, other organs develop, such as bone, muscle, and fat, that do not use glucose at the same rate as does the brain, leading to reduced whole-body weight-specific glucose utilization rates. For example, in fetal sheep, glucose utilization rates at 75 days (50\% of gestation) average $9.4 \mathrm{mg} / \mathrm{kg} / \mathrm{min}$ but at 140 days or $93 \%$ of gestation average $4.9 \mathrm{mg} / \mathrm{kg} / \mathrm{min}$. Similarly, in human neonates, glucose production rates among preterm infants at about 28 weeks' gestation average about 6-8 $\mathrm{mg} / \mathrm{min} / \mathrm{kg}$ while among term infants average 3-5 $\mathrm{mg} / \mathrm{min} / \mathrm{kg}[6,26]$.

Studies in both animals and humans have shown that glucose utilization is directly related to plasma glucose concentration, particularly in the brain. While it remains controversial whether and how short-term (minutes to a few hours) reductions in plasma glucose concentration affect significant aspects of development, particularly in the brain, it appears clearer that long-term, time-averaged low glucose concentrations contribute to reduced growth and brain development [27]. This occurs despite several organs, including the brain, developing up-regulation of tissue glucose transporters, an apparent natural adaptation to enhance glucose uptake capacity when plasma glucose concentrations are low and remain that way [28].

In contrast, long-term, time-averaged hyperglycemia tends to reduce glucose and insulin sensitivity and thus the capacity for glucose utilization, an apparent natural adaptation to limit glucose toxicity [28]. Unfortunately, hyperglycemia is an all too common problem in preterm infants. The most common cause is excessive intravenous glucose infusion, particularly when stress in the newborn preterm infant promotes glucose production and diminishes glucose utilization. Stress-reactive hormones such as adrenalin and noradrenalin increase in such infants in response to delivery, thermal instability, hypovolemia and low blood pressure, and diseases such as sepsis that through endotoxin reduce vascular tone. These hormones (and their often infused pharmacological counterparts, dopamine and dobutamine) inhibit insulin secretion, inhibit insulin action, and promote glycogen breakdown, all leading to hyperglycemia [29]. The same occurs with the stress hormones glucagon, which promotes glycogen breakdown, and cortisol (as well as pharmacologic counterparts such as hydrocortisone and decadron), which promotes protein breakdown and gluconeogenesis. Intravenous lipid infusion also contributes to hyperglycemia by competitively limiting glucose oxidation by substituting its carbon, and by promoting gluconeogenesis by providing lipid metabolic product co-factors that increase activity of gluconeogenic enzymes [30].

Hyperglycemia is best treated, therefore, by reducing intravenous glucose infusion rate, normalizing physiology and decreasing endogenous and exogenous catecholamines, and limiting intravenous lipid infusion. Because amino acids stimulate insulin production, earlier and higher rates of intravenous amino acid infusions might promote insulin production and its positive effects on diminishing hepatic glucose production and enhancing glucose utilization, which together should decrease plasma glucose concentrations and their adverse effects [31].

\section{Lipids}

There is much less known about the normal supply of lipids and their requirements for fetal growth and development. Among land mammal species, however, normal human fetal development involves considerable fat deposition in adipose tissue, from $10 \%$ of body weight in IUGR infants up to $20-25 \%$ of body weight in infants of obese, gestational diabetic mothers [26]. It is not known whether this late gestational growth of body fat, confined primarily and, among mammals, uniquely to adipose tissue, is important to produce in preterm infants. Currently, intravenous lipids are variably (among neonatology programs around the world) provided as early as the first day of life, even in very preterm, low birth weight infants, and advanced rather quickly to $3 \mathrm{~g} / \mathrm{kg} /$ day [32]. Attempts to increase lipid utilization with medium chain triglycerides that do not require the enzymes for transport of long chain triglycerides (carnitine palmitoyltransferase or $\mathrm{CPT}$ ) across the mitochondrial membrane for energy production or the use of supplemental carnitine to promote CPT activity and lipid oxidation have not proven to benefit lipid oxidation unless, in the case of carnitine, total intravenous nutrition is required for more than 2-3 weeks, due to the general absence of carnitine from basic intravenous lipid emulsions and the inability of the newborn infant to synthesize it [33].

Long-term reductions (days to weeks) in the supply of essential fatty acids, particularly the long chain polyunsaturated (PUFA) fatty acids of the $\omega-3$ category, can lead to essential fatty acid deficiency and limitation of neurological development (such fatty acids are required for myelin sheath development around both neurons and supporting glial cells and their absence leads to diminished neuronal development and synapse formation and function) $[34,35]$. There are among all of the intravenous 
lipid emulsions, however, sufficient essential fatty acids when given at $0.5 \mathrm{~g} / \mathrm{kg} / \mathrm{day}$, although many are unbalanced towards mostly $\omega-6$ rather than $\omega-3$ PUFAs. Specific neurological problems have been noted in preterm infants who do not get sufficient PUFAs, including delayed visual development [36]. Currently, there are a wide variety of intravenous lipid products that vary considerably in their supply of $\omega-3$ fatty acids (docosahexaenoic acid in particular), but all, as well as human milk, do not provide the amount of these essential fatty acids that accumulate in the normally growing fetal brain. Fetal white adipose tissue during last trimester accumulates about $67 \mathrm{mg} /$ day (mostly 22:6n-3). At $3.7 \mathrm{~g}$ fat/dl human milk with $0.2-0.4 \%$ fatty acids as $22: 6 \mathrm{n}-3$, a $1-\mathrm{kg}$ preterm infant fed at full enteral feeds of $180 \mathrm{ml} /$ day would get only 13 $25 \mathrm{mg}$ 22:6n-3/day, clearly below normal in utero accretion rates. Furthermore, a variety of studies have shown that preterm infants fed increased 22:6n-3 (docosahexaenoic acid) have higher visual acuity, particularly at 2 and 4 months corrected term age and improved Bayley mental development and MacArthur Communicative inventories at 12 months [36]. Thus, the current diet for these infants is deficient in this essential fatty acid; the long-term significance of this deficiency is not known, nor how these infants would develop if fed to sufficiency [2].

\section{Amino Acids and Protein}

Fetal animal studies and estimates from normal human fetal growth indicate that preterm infants generally require more amino acid supply than has customarily been given to such infants. At mid-gestation, fetal animals require from 3.5 to $4.6 \mathrm{~g} / \mathrm{kg} /$ day to sustain normal rates of fractional protein synthesis and growth $[37,38]$. Similarly, by the factorial method, Ziegler et al. [39] have estimated that the normal human fetus of the same gestational age requires $4 \mathrm{~g} / \mathrm{kg} / \mathrm{day}$. This rate of requirement is ongoing. There is no justification for short- or longterm interruption of amino acid supply, as happens when preterm infants are born and customarily are not given much in the way of intravenous (or enteral) amino acids, not just on the first day of life, but often for several days up to 1-2 weeks after birth. Fear of amino acid toxicity, uremia, and metabolic acidosis lingers, a problem left over from the earliest days of intravenous amino acid nutrition when solutions that were unbalanced away from essential amino acids and high in non-essential and potentially toxic (glycine, methionine, phenylalanine) were used. More recent solutions have reversed this pattern of amino acid supply and diminished markedly such possible toxicities [40, 41]. Furthermore, some increase in blood urea nitrogen is expected when the amino acids are oxidized, which they are quite readily in both the fetus and newborn preterm infant, and the ammonia by-product is successfully detoxified in the liver via the urea cycle. Unless there is simultaneous, severe pre-renal reductions in glomerular blood flow or glomerular filtration rate (often a result of fetal-neonatal hypoxic-ischemic damage), such increases in urea from normal rates of amino acid supply and oxidation are minimal and not known to be toxic $[42,43]$.

At the same time, many studies now have documented very clearly that there is a linear increase in both amino acid oxidation and amino acid synthesis into net protein accretion in relation to amino acid supply, at least up to 3.5 $\mathrm{g} / \mathrm{kg} /$ day $[41,44]$. The key, therefore, to prevent amino acid toxicity but to provide the necessary amount of amino acids for protein synthesis, net protein accretion, and growth is to give the right amount at the right time. Between 24 and 30 weeks, amino acid requirements are $3.6-4.8 \mathrm{~g} / \mathrm{kg} /$ day. Between 30 and 36 weeks, fractional growth rate decreases, as does the protein requirement for growth, to $2-3 \mathrm{~g} / \mathrm{kg} /$ day. At term, protein requirements decrease to those of the normal breastfed infant, or $1.5-2 \mathrm{~g} / \mathrm{kg} / \mathrm{day}$.

\section{Insulin}

Insulin is the principal anabolic hormone in the fetus, enhancing protein synthesis and reducing protein breakdown [45]. Insulin production begins as early as the midtrimester or around 15 weeks of gestation and increases to term values by $80 \%$ or so of term [46]. Absence of insulin in the fetus, as in infants with pancreatic agenesis, slows but does not stop growth, demonstrating that insulin is important but not essential for growth. Extra supply of insulin by itself without providing optimal amounts of amino acids and energy, cannot promote growth. There is no evidence, yet, that insulin infusion to 'enhance' nutrition (intravenously or enterally) of preterm infants, even extremely low birth weight (ELBW), very preterm infants, is beneficial, and there are many potential problems [45]. For the most part, insulin treatment to increase growth will simply make the baby fatter.

\section{Intravenous Nutrition Strategy}

Based on these principals of intravenous nutrition and nutritional substrate, oxygen, and anabolic hormone requirements the following guidelines are suggested for early and sustained intravenous nutrition to newborn, very preterm infants [5] (table 1). 
Table 1. Early feeding strategies [data taken from 5]

Day 0, admission to NICU: begin intravenous nutrition solution

- $\mathrm{A} \mathrm{D}_{7.5}+5 \%$ amino acid (AA) solution administered at $60 \mathrm{ml} /$ $\mathrm{kg} / 24 \mathrm{~h}$ will provide $3 \mathrm{~g} \mathrm{AA} / \mathrm{kg} / 24 \mathrm{~h}$ and meet most AA requirements for protein synthesis and net protein accretion, even for infants born as early as 25-27 weeks' gestation

- Additional fluids can be added as needed for total fluid intake of $80-100 \mathrm{ml} / \mathrm{kg} /$ day

- This approach allows AAs to be started immediately without waiting for 'TPN' prescriptions to be formulated

- This approach also allows for adjustments of total fluids, electrolytes, and glucose without needing to change the TPN prescription

Days 1-2

- Advance AAs to and keep total protein intake (IV + enteral) at $4.0 \mathrm{~g} / \mathrm{kg} /$ day (at 24-30 weeks; less for older gestations)

- Add glucose and lipids 'as tolerated', limiting glucose to $<10$ $\mathrm{mg} / \mathrm{kg} / \mathrm{min}$ and lipid to $<3.0 \mathrm{~g} / \mathrm{kg} /$ day. Adjust glucose and lipid infusions to keep plasma glucose concentrations $>50$ $\mathrm{mg} / \mathrm{dl}$ and $<100 \mathrm{mg} / \mathrm{dl}$ and plasma triglyceride concentrations $<150 \mathrm{mg} / \mathrm{dl}$

Days 1-2 and beyond

- Begin enteral feedings, using colostrum or milk whenever possible

- Volume and rate of advancement of feedings depend on gestational age, condition, and response, but slow advancement appears safer than rapid advancement

\section{Enteral Nutrition in Preterm Infants}

Unfortunately, despite the obvious need for early intravenous feeding of total nutritional requirements for preterm infants, there are many adverse consequences of intravenous feeding without any enteral nutrition [45, 47]. The absence of food in the gastrointestinal tract produces mucosal and villous atrophy and reduction of enzymes necessary for digestion and substrate absorption [47]. Trophic hormones normally produced in the mouth, stomach, and gut in response to enteral feeding are diminished. A variety of immune deficits also develop, including decreased mucosal IgA from Peyer's patches and increased production of adhesion molecules and polymorphonuclear cell attraction, all with the potential to increase the incidence and severity of the systemic inflammatory response syndrome $[48,49]$. Necrotizing enterocolitis (NEC) may be a direct result of such changes when enteral feeding is then introduced along with the pathogenic bacteria that by now are commonly part of the infant's skin, pharyngeal, tracheal, and gastrointestinal flora $[1,49]$. Added to this burden of actual and potential pathology, prolonged intravenous infusions of glucose and amino acids lead to diminished insulin action to promote glucose utilization, resulting in glucose intolerance and hyperglycemia [50].

Why then is there such common delay in early enteral nutrition in preterm infants? The most common reasons for delayed initiation and limited advancement of enteral feedings in preterm infants are the concerns for increasing the risk of NEC and the known immaturity of a number of physiological and hormonal systems at early gestational ages.

Despite concerns that enteral feedings are associated with NEC in extremely low birth weight and preterm infants, however, there have been no multicenter randomized controlled trials to evaluate the impact of different enteral or enteral + intravenous feeding strategies on the development of NEC [1]. Preterm birth is the one risk factor that continues to stand out above all others [51]. Feeding strategies, such as when to initiate enteral feedings and how fast to advance feedings, as well as which enteral product to use (milk, $20 \mathrm{kcal} / \mathrm{oz}$ formula, preterm formula, elemental formula, or experimental concoctions that attempt to mimic amniotic fluid), remain controversial. While fresh human milk does appear to decrease the risk of NEC, the amount required for this protective effect is not known (e.g., does minimal enteral nutrition with milk produce the same outcome for reducing NEC as does full enteral feeding with milk?). Furthermore, the influence of fortifiers and other additives in milk has not been tested rigorously for effects on NEC or other gastrointestinal complications. There also is little consensus about whether or not to feed enterally in the presence of umbilical artery (or vein) catheters, a patent ductus arteriosus (or how severe that PDA must be), use of low-dose dopamine, or low-dose indomethacin. Simultaneous use of indomethacin and physiological doses of hydrocortisone has been associated with increased risk of intestinal perforation, but only one study has convincingly shown that correlation [52].

Despite such concerns, there is clear evidence that promoting early enteral nutrition is beneficial. Animal studies have shown that early enteral feeding prevents gut atrophy, appears to stimulate maturation of the gastrointestinal system, may actually enhance eventual feeding tolerance, and may reduce the incidence of NEC, especially when colostrum and human milk are used [53].

The most common approach to successfully initiating and then advancing enteral feeding is to use the 'minimal enteral feeding' (MEF) strategy [54]. MEF generally refers to small amounts of enteral feedings of formula and/or breast milk at intakes of $5-25 \mathrm{ml} / \mathrm{kg} /$ day. MEFs also are 
called 'priming' feedings because of their role in stimulating many aspects of gut function, 'trophic' feedings for their positive impact on gut growth, and 'non-nutritive' feedings to indicate that they are not intended to be a primary source of nutrition, at least initially, as they do increase the rate at which full enteral feedings can be developed.

Regarding the efficacy of MEF, studies universally have shown a shorter time to full enteral feeds, faster weight gain, less feeding intolerance, less need for phototherapy, enhanced serum gastrin concentrations, enhanced maturation of the small intestine function, lower bilirubin concentrations, and shorter duration of hospitalization. As for safety concerns, there appears to be no increased incidence of NEC in infants who receive MEF, particularly when the mother's own milk is used; more recent studies, in fact, have shown reduced rates of NEC, although there has been little data collected to define associated risks, particularly those of prolonged intravenous feeding (risk of catheter sepsis, other catheterrelated complications, hepatic disorders, and so forth). There also have been few studies that have specifically addressed the optimal time to start MEF in terms of safety and efficacy. In stable preterm infants, starting MEF on day 1-2 is reasonable and cautious advances of $<20$ $\mathrm{ml} / \mathrm{kg} /$ day do not necessarily increase the incidence of NEC, although other studies have shown that rapid advancement of enteral feedings tends to increase the risk of NEC. Most groups that have initiated rigorous feeding protocols that include strict attention to reducing the risks of prolonged intravenous feeding (and these vary considerably among the groups) have noted a reduction in rates of NEC $[53,55,56]$.

Breast milk is the optimal enteral feeding. Additionally, nearly all studies demonstrate that breast milk confers a protective advantage against the development of NEC [57-61]. This advantage appears specific to fresh milk from each infant's own mother, not to banked milk, although this issue remains controversial with some studies showing dramatically opposing outcomes [61, 62]. Dilute formulas and dilute milk fail to provide sufficient energy intake and they fail to stimulate normal motor activity of the gastrointestinal tract. The higher protein intake in preterm formula may confer a neurocognitive developmental advantage compared to term formula preparations [15-17].

There are relatively few contraindications to MEF. Generally, MEF should be used cautiously in any situation associated with either marked gut hypoxia or associated with decreased intestinal blood flow, such as cases of fe- tal/neonatal 'asphyxia' (hypoxic-ischemic injury to the gut), persistent severe hypoxemia, hypotension, marked diastolic intestinal blood flow 'steal' secondary to a patent ductus arteriosus, and transient decreased superior mesenteric artery blood flow caused by rapid, high-dose, intravenous bolus infusions of indomethacin.

As for the mode of enteral feedings, bolus versus continuous drip, there appear to be almost as many different approaches as there have been different trials to determine the best mode [63-67]. Generally, slow bolus feedings (those lasting at least $30 \mathrm{~min}$ to an hour or two) may be preferable to continuous feeds, but this is highly controversial and institution-dependent [55]. Transpyloric feedings are used by some groups, particularly when gastroesophageal reflux is clinically serious, but no data exist to support their more routine use in preterm infants regarding efficacy and safety.

While delayed onset and slow advances of enteral feeding appear to reduce the risk of NEC, others are concerned that when feeding finally is introduced, more highly pathogenic bacteria will now enter the gut and increase the risk of NEC. Indeed, NEC does not occur in the fetus, indicating that postnatal feeding practices, particularly the introduction of bacteria into the gut, are responsible for NEC. Several groups now have started testing whether probiotics added to early enteral feeds could reduce the incidence of NEC even further [68]. Others have been concerned that the probiotic organisms themselves might induce sepsis and fungemia $[69,70]$. A recent meta-analysis of seven relevant studies found a reduced risk for NEC in the probiotic group versus controls and no difference between the groups for sepsis from any organism, including the probiotic Lactobacillus species, or fungemia from Saccharomyces species [71]. There also was a reduced risk of death from all causes in the probiotic groups compared to the control groups and a reduction in the time to reach full enteral feedings. Further studies are needed to determine the optimal species of probiotic organisms to use, their dose, when to start them, and whether they only confer an advantage (if they do) in formula-fed infants versus milk-fed infants.

\section{Summary of Fetal Based Nutrition of the Preterm Infant}

Oxygen deficit leads to fetal growth failure. It still is uncertain at what blood $\mathrm{PaO}_{2}, \mathrm{SaO}_{2}$, and $\mathrm{O}_{2}$ content this becomes significant. Glucose supply and concentration regulate growth. GUR decreases from $8 \mathrm{mg} / \mathrm{kg} / \mathrm{min}$ at 
Table 2. Fetal vs. very preterm neonatal nutrition [data taken from 3]

Normal fetal nutrition has several unique features:

- Amino acids are pumped into the fetus at rates and concentrations that are higher than the fetus can use

- The excess amino acid load is oxidized for energy

- Glucose is taken up and used to meet energy needs

In contrast, with more 'customary' nutrition of the preterm infants:

- Glucose is pumped into the infant at rates and concentrations that are higher than the infant can use

- The excess glucose load produces hyperglycemia

- Amino acids are provided at rates that are less than needed for normal growth rates

Therefore, to improve early nutrition of the preterm infant, and to more closely follow the minimal requirements for nutrition established by the growth of the normal fetus at the same gestational age, one should:

- Pump amino acids into the infant at rates and concentrations just higher than the infant can use: e.g., 3-4 g/kg/day in infants $<30$ weeks' gestation

- The excess amino acid load will be oxidized, producing useful energy

- Provide just enough glucose to meet glucose needs (6-10 mg/ $\mathrm{kg} / \mathrm{min}=27-42 \mathrm{kcal} / \mathrm{kg} /$ day)

- Provide just enough lipid to meet additional energy (and EFA) needs $(2-3 \mathrm{~g} / \mathrm{kg} /$ day $=18-36 \mathrm{kcal} / \mathrm{kg} /$ day $)$

mid-gestation to $4 \mathrm{mg} / \mathrm{kg} / \mathrm{min}$ at term. Glucose concentrations should average $>55 \mathrm{mg} / \mathrm{dl}(\sim 3 \mathrm{mM})$, but $<120$ $\mathrm{mg} / \mathrm{dl}(\sim 6 \mathrm{mM})$. Amino acid supply must be high enough (e.g., $4 \mathrm{~g} / \mathrm{kg} /$ day at $24-30$ weeks) to meet the rapid protein synthetic rates characteristic of normal fetal growth, although amino acid supply rate, and which ones, for IUGR infants remains uncertain. Amino acid concentrations are important for growth and are unique, particularly with greater need for relatively higher concentrations of essential amino acids. Growth of adipose tissue requires glucose and fatty acids - these usually are provided in excess. Essential membranes require a unique mix of mostly long chain essential fatty acids (as well as sufficient protein). Insulin concentrations that result from such nutrition probably are sufficient for normal growth (table 2).

\section{Special Consideration of Infants with Intrauterine Growth Restriction}

Many (from 15 to $50 \%$, depending on study and population surveyed) preterm infants already are growth-restricted at birth, or get that way in the NICU $(100 \%$ by term in most centers). It is reasonable, therefore, to consider whether increased supplies of amino acids and protein would improve growth in the IUGR neonate that already have undergone prenatal metabolic and growth adaptations that might produce unique nutritional requirements. In this regard, it is important to note that the IUGR phenotype includes decreased pancreatic development, insulin secretion capacity, and decreased capacity for amino acid synthesis into protein and cell growth. Here, the literature currently is mixed and does not provide optimal guidelines. For example, mixed amino acids increase protein accretion in normal and short-term (6 days) IUGR ovine fetuses [72]. In contrast, studies in chronically growth-restricted fetal sheep from placental insufficiency (smaller than normal placenta with glucose and amino acid transport deficits, more consistent with most human cases of IUGR) have shown that regulators of protein translation and synthesis in skeletal muscle and liver are decreased, while inhibitors of these pathways are increased. More recent and yet unpublished studies in IUGR fetal sheep have shown that acute amino acid infusion does not increase the intracellular protein regulators of protein synthesis in IUGR fetuses and there is a decreased amount of phosphorylated (activated) 4EBP1 (inhibitor of protein synthesis signal transduction) that is not restored to control values with additional amino acids [73]. It is possible, therefore, that protein synthesis in the chronically IUGR fetus might be refractory to increased supply of amino acids, and, therefore, the same rate of amino acid nutrition provided to a chronically IUGR infant might not produce the same increase in growth as in a normally growing fetus born preterm. Also, since the IUGR fetus has an up-regulated capacity to take up glucose, attempts to infuse higher rates of glucose intravenously might produce both lactic acidosis and fat production more readily than in the normal fetus. Most likely such conditions apply to the most severely growth-restricted fetuses. These conditions obviously will require both animal and human investigation before recommendations about optimal amino acid, protein, and energy nutrition for IUGR infants can be made.

\section{Some Final Thoughts and Words of Caution}

Both birth weight and rate of weight gain predict childhood overweight status [74]. Furthermore, Heird and Kashyap showed that at appropriate protein and calorie intakes in enterally fed, preterm infants, more energy only produced fatter infants; they indeed were heavier, 
but they did not show increased growth of bone length, body length, head circumference, or brain size (by interpolation) [75]. Many studies now are showing clearly that excessive growth, primary or by catch up, leads to later life complications of obesity, insulin resistance, and diabetes $[74,76]$. Thus, it is essential to develop strategies to feed preterm infants what they need to maintain normal in utero growth rates. This should be started at birth. Feeding less than this will continue to produce growthrestricted infants with limited growth capacity, particularly of the brain and its many essential functions. Feeding more than this, primarily of energy (fat and carbohydrate) and producing obesity (increased weight-length ratio) clearly may be harmful.

\section{References}

1 Parish A, Bhatia J: Feeding strategies in the ELBW infant. J Perinatol 2008;28(suppl): S18-S20.

2 Hay WW Jr: Nutrient supplies for optimal health in preterm infants. Current issues on the nutrition of the preterm infant. J Pediatr Gastroenterol Nutr 2007;45(suppl):S163S169.

-3 Hay WW Jr: Early postnatal nutritional requirements of the very preterm infant based on a presentation at the NICHD-AAP Workshop on Research in Neonatology. J Perinatol 2006;26(suppl):S13-S18.

4 Thureen PJ, Hay WW Jr: Nutritional requirements of the very low birth weight infant; in Neu J (ed): Gastroenterology and Nutrition. Philadelphia, Elsevier Science, 2008, pp 208-222.

5 Hay WW Jr: Intravenous nutrition for the extremely preterm infant; in Pereira G (ed): Nutrition of the Premature Infant. Rio de Janeiro, Medbook Editora Cientifica, 2008, pp 141-178.

6 Hay WW Jr: Nutrition and development of the fetus: carbohydrate and lipid metabolism; in Walker WA, Watkins JB, Duggan CP (eds): Nutrition in Pediatrics. Basic Science and Clinical Applications, ed 4. Hamilton, Decker, 2008, pp 311-325.

7 Hay WW Jr, Brown LD, Regnault TRH: Fetal requirements and placental transfer of nitrogenous compounds; in Polin RA, Fox WW, Abman SH (eds): Fetal and Neonatal Physiology, ed 4. Philadelphia, ElsevierSaunders, 2008, in press.

8 American Academy of Pediatrics Committee on Nutrition: Nutritional needs of lowbirth-weight infants. Pediatrics 1985;76: 976-986.

-9 Dancis J, O’Connell JR, Holt LE Jr: A grid for recording the weight of premature infants. J Pediatr 1948;33:570-572.

-10 Ehrenkranz RA: Growth outcomes of very low-birth weight infants in the newborn intensive care unit. Clin Perinatol 2000;27: 325-345.

-11 Carlson SJ, Ziegler EE: Nutrient intakes and growth of very low birth weight infants. J Perinatol 1998;18:252-258.
2 Dinerstein A, Nieto RM, Solana CL, Perez GP, Otheguy LE, Larguia AM: Early and aggressive nutritional strategy (parenteral and enteral) decreases postnatal growth failure in very low birth weight infants. J Perinatol 2006;26:436-442.

13 Smart JL: Vulnerability of developing brain to undernutrition. Ups J Med Sci 1990; 48(suppl):21-41.

14 Smart JL: Critical periods in brain development; in Bock GR, Whelan J (eds): The Childhood Environment and Adult Disease. Ciba Found Symp 156. Chichester, Wiley, 1991, pp 109-128.

15 Huppi PS: Nutrition for the brain. Commentary on the article by Isaacs et al, p. 308. Pediatr Res 2008;63:229-231.

16 Lodygensky GA, Seghier ML, Warfield SK, Tolsa CB, Sizoonenko S, Lazeyras F, Huppi PS: Intrauterine growth restriction affects the preterm infant's hippocampus. Pediatr Res 2008;63:438-443

17 Isaacs EB, Gadian DG, Sabatini S, Chong WK, Quinn BT, Fischl BR, Lucas A: The effect of early human diet on caudate volumes and IQ. Pediatr Res 2008;63:229-231.

18 Milley JR: Ovine fetal leucine kinetics and protein metabolism during decreased oxygen availability. Am J Physiol 1998;274: E618-E626.

19 Liu L, Simon MC: Regulation of transcription and translation by hypoxia. Cancer Biol Ther 2004;3:492-497.

20 Alverson DC: The physiologic impact of anemia in the neonate. Clin Perinatol 1995;22: 609-625.

21 Stockman JA 3rd, Clark DA: Weight gain: a response to transfusion in selected preterm infants. Am J Dis Child 1984;138:828-830.

22 Kitanaka T, Alonso JG, Gilbert RD, Siu BL, Clements GK, Longo LD: Fetal responses to long-term hypoxemia in sheep. Am J Physiol 1989;256:R1348-R1354

23 Tin W: Oxygen therapy: 50 years of uncertainty. Pediatrics 2002;110:615-616.

24 Hay WW Jr: Nutrient delivery and metabolism in the fetus; in Hod M, Jovanovic L, Di Renzo G, DeLeiva A (eds): Textbook of Diabetes and Pregnancy, London, Dunitz, 2003, pp 201-221.
25 Say L, Gülmezoglu AM, Hofmeyr GJ: Maternal nutrient supplementation for suspected impaired fetal growth. The Cochrane Database of Systematic Reviews, No 1, 2003.

26 Battaglia FC, Meschia G: An Introduction to Fetal Physiology. Orlando, Academic Press, 1986, pp 100-135.

27 Lucas A, Morley R, Cole TJ: Adverse neurodevelopmental outcome of moderate neonatal hypoglycemia. BMJ 1988;297:13041308.

28 Das UG, Schroeder RE, Hay WW Jr, Devaskar SU: Time-dependent and tissue-specific effects of circulating glucose on fetal ovine glucose transporters. Am J Physiol 1999;276: R809-R817.

29 Hay WW Jr: Nutrition and development of the fetus: carbohydrate and lipid metabolism; in Walker, WA, Watkins JB, Duggan CP (eds): Nutrition in Pediatrics. Basic Science and Clinical Applications, ed 3. Hamilton, Decker, 2003, pp 449-470.

30 Sunehag A: The role of parenteral lipids in supporting gluconeogenesis in very premature infants. Pediatr Res 2003;54:480-486.

31 Micheli JL, Schutz Y: Protein; in Tsang RC, Lucas A, Uauy R, Zlotkin S (eds): Nutritional Needs of the Preterm Infant, Scientific Basis and Practical Guidelines. Pawling/NY, Caduceus Medical, 1993, pp 29-46.

32 Sellmayer A, Koletzko B: Long-chain polyunsaturated fatty acids and eicosanoids in infants - Physiological and pathophysiological aspects and open questions. Lipids 1999; 34:199-205.

33 Helms RA, Mauer EC, Hay WW Jr, Christensen ML, Storm MC: Effect of intravenous L-carnitine on growth and fat metabolism parameters during parenteral nutrition in neonates. J Parenter Enter Nutr 1990;14: 448-453.

34 Carlson SE: Docosahexaenoic acid and arachidonic acid in infant development. Semin Neonatol 2001;6:437-449.

35 Innis SM: Essential fatty acid transfer in fetal development. Placenta 2005;26(suppl A): S70-S75. 
-36 Carlson SE, Werkman SH, Rhodes PG, Tolley EA: Visual acuity development in healthy preterm infants: effect of marine oil supplementation. Am J Clin Nutr 1993;58:35-42.

-37 Meier PR, Peterson RG, Bonds DR, et al: Rates of protein synthesis and turnover in fetal life. Am J Physiol 1981;240:E320-E324.

-38 Ross JC, Fennessey PV, Wilkening RB, Battaglia FC, Meschia G: Placental transport and fetal utilization of leucine in a model of fetal growth retardation. Am J Physiol 1996;270: E491-E503.

-39 Ziegler EE, O’Donnell AM, Nelson SE, Fomon SJ: Body composition of the reference fetus. Growth 1976;40:329-341.

$\checkmark 40$ Heird WC, Hay W, Helms RA, Storm MC, Kashyap S, Dell RB: Pediatric parenteral amino acid mixture in low birth weight infants. Pediatrics 1988;81:41-50.

41 Thureen PJ, Melara D, Fennessey PV, Hay WW Jr: Effect of low versus high intravenous amino acid intake on very low birth weight infants in the early neonatal period. Pediatr Res 2003;53:24-32.

42 Ridout E, Melara D, Rottinghaus S, Thureen PJ: Blood urea nitrogen concentration as a marker of amino-acid intolerance in neonates with birthweight less than 1,250 g. J Perinatol 2005;25:130-133.

43 Reynolds RM, Bass KD, Thureen PJ: Achieving positive protein balance in the immediate postoperative period in neonates undergoing abdominal surgery. J Pediatr 2008;152: 63-67.

$\checkmark 44$ Denne SC, Poindexter BB: Evidence supporting early nutritional support with parenteral amino acid infusion. Semin Perinatol 2007;31:56-60.

-45 Poindexter BB, Karn CA, Denne SC: Exogenous insulin reduces proteolysis and protein synthesis in extremely low birth weight infants. J Pediatr 1998;132:948-953.

-46 Aldoretta PW, Gresores A, Carver TD, Hay WW Jr: Maturation of glucose-stimulated insulin secretion. Biol Neonate 1998;73:375386.

47 Neu J: Gastrointestinal development and meeting the nutritional needs of premature infants. Am J Clin Nut 2007;85:629S-634S.

-48 Zeigler EE, Thureen PJ, Carlson SJ: Aggressive nutrition of the very low birthweight infant. Clin Perinatol 2002;29:225-244.

-49 Neu J, Douglas-Escobar M, Lopez M: Microbes and the developing gastrointestinal tract. Nut Clin Pract 2007;22:174-182.

50 Stoll B, Patrycja PJ, Burrin DG: Continuous parenteral versus enteral nutrition induces glucose intolerance and hyperinsulinemia in neonatal piglets. Pediatric Academic Societies Annual Meeting, Publ 3050.2, 2008.

-51 Gordon PV, Swanson JR, Attridge JT, Clark $\mathrm{R}$ : Emerging trends in acquired neonatal intestinal disease: is it time to abandon Bell's criteria? J Perinatol 2007;27:661-671.
52 Watterberg KL, Gerdes JS, Cole CH, et al: Growth and neurodevelopmental outcomes after early low-dose hydrocortisone treatment in extremely low birth weight infants. Pediatrics 2004;114:1649-1657.

53 Pietz J, Achanti B, Lilien L, Stepka EC, Mehta SK: Prevention of necrotizing enterocolitis in preterm infants: a 20 -year experience. $\mathrm{Pe}$ diatrics 2007;119:e164-e170.

54 Lucas A, Bloom SR, Aynslety-Green A: Gut hormones and 'minimal enteral feeding'. Acta Paediatr Scand 1986;75:719-723.

55 Spritzer R, Koolen AMP, Baerts W, Fetter WPW, Lafeber HN, Sauer PJJ: A prolonged decline in the incidence of necrotizing enterocolitis after the introduction of a cautious feeding regimen. Acta Pediatr Scand 1988;77:909-911.

-56 Kamitsuka MD, Horton MK, Williams MA: The incidence of necrotizing enterocolitis after introducing standardized feeding schedules for infants between 1,250 and $2,500 \mathrm{~g}$ and less than 35 weeks' gestation. Pediatrics 2000;105:379-384.

57 Lucas A, Cole TJ: Breast milk and neonatal necrotizing enterocolitis. Lancet 1990;336: 1519-1523.

58 Schanler RJ, Shulman RJ, Lau C: Feeding strategies for premature infants: beneficial outcomes of feeding fortified human milk versus preterm formula. Pediatrics 1999;103: 1150-1157.

59 Sisk PM, Lovelady CA, Dillard RG, Gruber KJ, O'Shea TM: Early human milk feeding is associated with a lower risk of necrotizing enterocolitis in very low birth weight infants. J Perinatol 2007;27:428-433.

60 McGuire W, Anthony MY: Donor human milk versus formula for preventing necrotizing enterocolitis in preterm infants: systematic review. Arch Dis Child Fetal Neonatal Ed 2003;88:11-14.

-61 Boyd CA, Quigley MA, Brocklehurst P: Donor breast milk versus infant formula for preterm infants: systematic review and metaanalysis. Arch Dis Child Fetal Neonatal Ed 2007;92:169-175.

62 Schanler RJ, Lau C, Hurst NM, Smith EO: Randomized trial of donor human milk versus preterm formula as substitutes for mothers' own milk in the feeding of extremely premature infants. Pediatrics 2005;116:400 406.

63 Kennedy KA, Tyson JE: The Cochrane database of systematic reviews: early versus delayed initiation of progressive enteral feedings for parenterally fed low birth weight or preterm infants. The Cochrane Library 2004;3.
64 Ronnestad A, Abrahamsen TG, Medbo S, Reigstad H, Lossius K, Kaaresen PI, et al: Late-onset septicemia in a Norwegian national cohort of extremely premature infants receiving very early full human milk feeding. Pediatrics 2005;115:e269-e276.

65 Tyson JE, Kennedy KA: The Cochrane database of systematic reviews: trophic feedings for parenterally fed infants. The Cochrane Library 2005; 4 .

66 Berseth CL, Bisquera JA, Paje VU: Prolonging small feeding volumes early in life decreases the incidence of necrotizing enterocolitis in very low birth weight infants. Pediatrics 2003;111:529-534.

67 Schanler RJ, Shulman RJ, Lau C, Smith EO, Heitkemper MM: Feeding strategies for premature infants: randomized trial of gastrointestinal priming and tube-feeding method. Pediatrics 1999;103:434-439.

68 Satoh Y, Shinohara K, Umezaki H, Shoji H, Satoh H, Ohtsuka Y, Shiga S, Nagata S, Shimizu T, Yamashiro Y: Bifidobacteria prevents necrotizing enterocolitis and infection in preterm infants. Int $\mathrm{J}$ Probiot Prebiot 2007;2:149-154.

69 Land MH, Rouster-Stephens K, Woods CR, Cannon ML, Cnota J, Shetty AK: Lactobacillus sepsis associated with probiotic therapy. Pediatrics 2005;115:178-181.

70 Perapoch J, Planes AM, Querol A, Lopez V, Marinez-Bendayan I, Tormo R, et al: Fungemia with Saccharomyces cerevisiae in two newborns, only one of whom had been treated with ultra-levura. Eur J Clin Microbiol Infect Dis 2000;19:468-470.

71 Deshpande G, Rao S, Patole S: Probiotics for prevention of necrotizing enterocolitis in preterm neonates with very low birthweight: a systematic review of randomized controlled trials. Lancet 2007;369:1614-1620.

72 De Boo HA, van Zijl PL, Smith DE, Kulik W, Lafeber HN, Harding JE: Arginine and mixed amino acids increase protein accretion in the growth-restricted and normal ovine fetus by different mechanisms. Pediatr Res 2005;58:270-277.

73 Brown LD, Hay WW Jr: Amino acids fail to induce skeletal muscle 4E-BP1 phosphorylation in an ovine model of intrauterine growth restriction. Pediatric Research, PAS Annual Meeting, May 2006.

-74 Stettler N, Kumanyika SK, Katz SH, Zemel BS, Stallings VA: Rapid weight gain during infancy and obesity in young adulthood in a cohort of African-Americans. Am J Clin Nutr 2003;77:1374-1378.

77 Kashyap S, Schulze KF, Ramakrishnan R, Dell RB, Heird WC: Effects of protein and energy intakes on growth. J Pediatr 1987;110: 815.

76 Barker DJ: The developmental origins of adult disease. J Am Coll Nutr 2004;23 (suppl):588S-595S 